\title{
More on Regulation: A Reply to Stephen Weiner
}

Clark C. Havighurst, J.D.*

\section{EDITOR'S NOTE}

In Volume 3, Number 3 of this journal, Professor Havighurst wrote a brief Comment in which he observed that the function of health care cost-containment regulation is the rationing of health care resources, and argued that the fostering of health care consumers' and providers' free choice in the competitive marketplace is preferable to conventional cost-containment regulation as a mechanism for such rationing. He briefly outlined various reforms, including changes in federal tax treatment of health insurance premiums, aimed at implementing his approach.

Subsequently, in a Comment in Volume 4, Number 1, Stephen $M$. Weiner, then Chairman of the Massachusetts Rate Setting Commission, criticized Professor Havighurst's analysis by asserting that it failed to acknowledge the validity of regulation in the health care field; that it overemphasized free market economics; and that it failed to appreciate the essentially political nature of regulatory processes. Mr. Weiner argued that health care regulation is here to stay, and called for renewed efforts to clarify and implement appropriate relationships between health care regulation and (1) health care rationing, (2) health care planning, and (3) health care competition.

In the Comment below, Professor Havighurst replies both to specific statements in, and the general direction of, Mr. Weiner's critique, asserting that it inaccurately represented the earlier Havighurst Comment in several important respects. Professor Havighurst states, for example, that, Mr. Weiner's opinion notwithstanding, Havighurst-both in his earlier Comment and in his other writings-has considered extensively the political nature of regulation, and, furthermore, has been constructive in his critiques of regulation. He charges Mr. Weiner with attempting to stifle debate on the question of the volume and direction of health care regulation, and suggests that Weiner's criticisms may reflect a bias against the individual's right to choose for himself and to have his preferences registered in the economic marketplace.

\footnotetext{
* Professor of Law, Duke University School of Law.
} 
I was not flattered by the attention Stephen Weiner, writing in this journal, ${ }^{1}$ paid to my work, mostly because he paid so little. While purporting to discuss a brief editorial Comment ${ }^{2}$ that 1 wrote for an earlier edition, his attack clearly was aimed at a larger target. Had that target been the totality of my writing on health care regulation, I could not have complained, but he makes no reference to any of my lengthier papers, which were cited in my Comment and which provide a foundation for most of the conclusions it reached. Moreover, Mr. Weiner's specific complaints about gaps in my argument, and his apparent misunderstanding of my positions and of my mode of analysis, indicate, at best, a poorly recollected reading of my more deliberate work. It appears that Weiner became absorbed in attacking a different target, namely his own stereotype of a "free market" advocate. That he had a stereotype in mind appears in his tracing of my "intellectual antecedents" to "Chicago and The Brookings Institute [sic]." Such an indiscriminate lumping of the University of Chicago school of economics and The Brookings Institution, which are usually thought to be ideologically opposed, indicates either a weak knowledge of the ideological landscape ${ }^{3}$ or an attempt to isolate a substantial number of respected scholars.

I felt called upon to reply to Mr. Weiner's paper because it has a patina of scholarship that will make it popular among those who need the comfort of his conclusions. Perhaps it will be possible, in addition to setting the record straight on some specific points, to reveal the substance of his dispute with me so that the true issues will appear and some false ones can be put aside.

Before getting to the finer points, I must challenge some direct misstatements. Weiner accuses me of "assuming" that, because other kinds of

\footnotetext{
'Weiner, Governmental Regulation of Health Care: A Response to Some Criticisms Voiced by Proponents of a "Free Market," 4 AM. J. L. \& MED. 15 (1978).

${ }^{2}$ Havighurst, Health Care Cost-Containment Regulation: Prospects and an Alternative, 3 AM. J. L. \& MED. 309 (1977).

At one point, Weiner tries to score a debating point by claiming that my proposal to use limited tax credits to subsidize health insurance purchases is inconsistent with my "biases." Weiner, supra note 1 , at 31 . In order to lecture me on the implications of my own supposed philosophy, Weiner must be wedded very firmly to his stereotype, since one would expect my philosophy to be revealed in its application. In any event, my proposal was to remove an existing distortion of private incentives (see text accompanying notes 27-28 infra), not to manipulate them, as Weiner suggests. Further, there is an important distinction between the conservative laissez faire tradition, with which $\mathrm{Mr}$. Weiner seems to think he is contending, and the approach of a pragmatic liberal such as Charles L. Schultze (formerly of Brookings) in his 1977 book The Public Use of Private Interest. Indeed, this title, suggesting that private interest is not sacrosanct but is there to be used by the public, probably would offend a true conservative. I am myself quite comfortable with a pragmatic approach that would provide for direct government intervention only where indirect approaches—ordering incentives and strengthening competitive forces-are demonstrably inadequate. Later discussion in the present Comment suggests the possibility that Weiner himself could be philosophically content with this approach.
} 
regulation have failed, health sector regulation also must fail. ${ }^{4}$ What I said, at the outset of my analysis, was that, "[w]hile the earlier analogies [to older regulatory efforts] were useful in framing the pertinent questions, it is clear that health sector regulation is in many respects sui generis," 3 and my argument proceeded exclusively on that basis. Weiner criticizes me at length for ignoring the possibility that combining planning and regulation may pay great dividends, ${ }^{6}$ but I said, "The HSAs, as local planning agencies, could make an interesting difference if they were dedicated to 'hard' planning. ..."7 I also concluded that "a toughminded, planning-oriented approach ... seems not to be in the political cards." 8 I have more fully explored this matter, which I find to be of great interest, in other writing. ${ }^{9}$

Weiner seems to argue that, working from an economic model, I fail to appreciate the importance of politics and political bargaining in determining the outcome of regulatory processes. But, by my count, I have published roughly 160 pages in numerous journals specifically considering health sector regulation as a political process. ${ }^{10}$ This figure excludes the Comment that Weiner purports to be criticizing, which analyzed regulation exclusively in political terms. My goal throughout has been to do precisely what Weiner says that I have a "responsibility" 11 to do. Given the amount of ink I have used in trying to assess the politics of regulation in the health sector, I am surprised by Weiner's reference to my conclusions as "assumptions" 12 and his attribution to me of a belief that government regulation is always economically and socially irrational ${ }^{13}$ and of an "a priori" belief that regulation is doomed to fail. ${ }^{14}$ Contrary to Weiner's repeated assertions, I believe the record will show that my criticisms of regulation have been constructive and that the design of regulation today reflects

\footnotetext{
Weiner, supra note 1 , at 16.

5 Havighurst, supra note 2, at 312.

6einer, supra note 1 , at 26-30.

${ }^{7}$ Havighurst, supra note 2, at 312 n.7.

Id. at 316.

${ }^{\circ}$ Havighurst, Regulation of Health Facilities and Services by "Certificate of Need," 59 VA. L. Rev. 1143, 1194-1204 (1973).

${ }^{10}$ Havighurst, Blumstein, \& Bovbjerg, Strategies in Underwriting the Costs of Catastrophic Disease, L. \& Contemp. Prob., Autumn 1976, at 122, 138-65 (1976); Havighurst \& Blumstein, Coping with Quality/Cost Trade-Offs in Medical Care: The Role of PSROs, 70 Nw. U. L. REv. 6, 20-68 (1975); Havighurst, Federal Regulation of the Health Care Delivery System: A Foreword in the Nature of a "Package Insert," 6 U. Tol. L. REv. 577 (1975); Havighurst \& Bovbjerg, Professional Standards Review Organizations and Health Maintenance Organizations: Are They Compatible? 1975 Utah L. REv. 381, $401-21$ (1975); Havighurst, Health Maintenance Organizations and the Health Planners, 1978 UraH L. Rev. 123, 140-54 (1978); Havighurst, supra note 9, at 1178-1218.

1 Weiner, supra note 1, at 20.

$12 \mathrm{Jd}$. at 16.

13 Id. at 18 .

14 Id. at 24.
} 
many steps taken in an attempt to avert hazards that I helped to point out.

My assessment of health sector cost-containment regulation was gloomy precisely because I regard rationing health care, reducing what passes for "the quality of care," to be a particularly difficult political assignment, as compared, say, with limiting the profits of a public utility. I tried to prove that obvious point by analyzing the highly instructive rhetoric surrounding cost-containment regulation, which is usually described as having as its noncontroversial goals the improvement of the quality of care and the elimination of "inefficiency," "fat," "unnecessary care," and "duplication." Weiner contradicts, without evidence, ${ }^{15}$ my documented observation that politically exposed regulators are reticent about acknowledging their rationing function. ${ }^{16}$ The point is not crucial, but it still seems to me to be correct. (Indeed, the subject's political touchiness was confirmed again recently when Senator Kennedy, on the Public Broadcasting System's MacNeil/Lehrer Report, dodged a direct question by the AMA's executive vice president about his views on rationing.) I cannot tell whether, in disputing my argument that politics makes it hard for regulators to be candid and therefore, presumably, to be effective rationers of care, Weiner intends to deny my larger point that the cost-containment job is difficult. Probably he would take the position that most regulators take-namely that the job is difficult but not impossible. Such a stance conveniently explains past deficiencies while also justifying a larger regulatory budget for the future.

Weiner attributes to me the view that it is inappropriate for regulators to seek to shift the rationing burden to providers. ${ }^{17}$ While I did question some of the assumptions behind that strategy and doubted its success (because of the politics of what I called a "'hot potato' game"), I denied neither the need to push ahead with this approach nor the conscientiousness of the regulators who have adopted it. Indeed, I characterized regulatory "arbitrariness," designed to clamp a lid on the resources available to providers and thus force rationing, as probably "the most responsible regulatory policy because it is the most likely to be effective." 18 The probable defeat, as of this writing, of the Carter Administration's hospital costcontainment bill, which would have overcome some of the political diffculties in rationing care (though it had other defects), vindicates my political assessment that providers, by talking about the quality of care, usually can avoid having the rationing burden imposed on them. I do not disagree with Weiner's reasons for supporting provider rationing, mostly because

\footnotetext{
${ }^{15} I d$. at 21 .

${ }^{16}$ Havighurst, supra note 2 , at 313 .

${ }^{17}$ Weiner, supra note 1 , at 22.

${ }^{18}$ Havighurst, supra note 2, at 317 (emphasis added).
} 
they are close to ideas that were alluded to in my Comment and that James Blumstein and I elaborated fully some time ago. ${ }^{1 \mathrm{~s}}$

My further points should help to isolate Weiner's real basis for resisting the logic of my arguments. Weiner's reference ${ }^{20}$ to Victor Goldberg's article, ${ }^{21}$ which analogizes regulation to an "administered contract," was interesting to me, though not because it proves any of Weiner's points. Weiner's description of relations under private "administered contracts" 22 is very close to what I believe relations should be between consumers and providers, on the one hand, and competing health plans, on the otherwhether they are of the insurance, the service-plan, the HMO, or some new hybrid variety. Adequate attention to my work would have led Weiner to perceive that, far from wishing to return exclusively to "discrete transactions" ${ }^{23}$ - whatever that term means in this context ${ }^{24}$ - I regard "administered contracts" as the best available mechanism for resolving most of the problems of the health care industry. Indeed, it is the proponents of regulation who need a lesson in "administered contracts," for they regularly cite consumer ignorance, third-party payment, and physician control of demand as making regulation inevitable, and they refuse to see the myriad possibilities for overcoming these problems that are inherent in the institution of private contract. I differ with such persons not over the consumer's need to escape the "discrete transactions" marketplace and to have the aid of an expert intermediary in dealing with providers, but over whether that intermediary must be a public rather than a private entity.

The advantages of private administered contracts over public regulation are too numerous to go into here. In any event, Weiner, surprisingly, appears to agree with me, for in his footnote 51 , crediting me with "recognizing" that HMOs are a private, consensual vehicle for rationing care-that is, an administered contract-, he says, "If consensual rationing can be as stringent as government rationing, it is undoubtedly to be pre-

${ }^{19}$ Havighurst \& Blumstein, Coping with Quality/Cost Trade-Offs in Medical Care: The Role of PSROs, $70 \mathrm{Nw}$. U. L. Rev. 6 (1975).

${ }^{20}$ Weiner, supra note 1 , at 17-18.

${ }^{21}$ Goldberg, Regulation and Administered Contracts, 7 THE BELL JourNal of Economics 426 (1976).

22 The "administered contract" exhibits either or both of two elements. First, it involves a contractual relationship between principals that continues for an extended period of time, rather than occurring only at a fixed point in time, and that establishes a framework for redefining contractual terms and conditions as circumstances change over time. Second, this relationship involves a reliance upon agents for the fulfillment of such functions as gathering and analyzing essential information, making binding decisions, and adjusting the terms of the ongoing contractual relationships between the principals.

Weiner, supra note 1 , at 17 (footnote omitted).

${ }^{23}$ Id.

${ }^{24}$ Presumably it would refer to doctor-patient transactions conducted on a fee-for-service basis without third-party financing. 
ferred." 25 But my argument was that, if only government did not distort private incentives through its tax rules governing employer-paid insurance premiums, private rationing could be not merely as stringent as government rationing but more so (because it would be less political and therefore less concerned with symbolism). ${ }^{26}$ Weiner cannot accept my argument because he cannot conceive of this possibility as a general proposition, though he must concede it with respect to HMOs because they have economized circles around the regulated system. The main apparent reason for his underestimating the power of private incentives as embodied in administered contracts is that he seems not to understand the mechanism-let alone appreciate the impact-of the tax law.

My paper sketched the market-oriented alternative only briefly, but apparently I should have explained more fully how it is that the tax law encourages over-insurance (including excessive liberality in claims payment) and thus why changing that law probably would make a greater difference than regulation can make. Weiner devotes two paragraphs ${ }^{27}$ to disputing that the employer's business deduction and the employee's limited personal deduction of their respective health insurance premiums create any significant problem. But it is not these deductions so much as the total and unlimited exclusion of the employer's contributions from the employee's taxable wages (for both income and payroll tax purposes) that induces the purchase of excessive insurance. By this mechanism, the tax law makes it highly advantageous for as much health care as possible to be paid for through employer-purchased insurance. A further result is that private incentives to reduce premiums through cost-containment efforts are impaired, leaving us no apparent alternative but to turn to government for help. My argument is that, with the right incentives and more room for competition, the private sector could discharge the responsibility for cost-containment better than government-though it may not, for complex reasons, be anxious to do so. ${ }^{28}$

There is plenty to argue about in this conclusion, but, if one uses Weiner's own test from his footnote 51 , the issues are strictly empirical, not theoretical: Would private-sector cost containment in fact be as strin-

\footnotetext{
28 Weiner, supra note 1 , at $\mathbf{3 2}$ n.51.

${ }^{20}$ It should be recognized that unions and employers have a "political" relationship with the workers and necessarily are concerned with symbolism in providing health benefits. The tax law exacerbates this problem by transferring some of the cost of eschewing stringency from the parties to the federal government. If the tax law were changed and if the union leadership still preferred lavish health care at the expense of increased take-home pay, the high cost would be borne solely by the rank and file, who would have an incentive to demand a different plan. If they failed to do so, that presumably would reflect their choice, and, even if we did not agree with it, it would be hard to find any reason to intervene.

27 Weiner, supra note 1 , at 30-31.

${ }^{28}$ Insurance companies, in particular, would rather not have this ticklish responsibility. Competition should force them to accept it, however. See Havighurst, Professional Restraints on Innovation in Health Care Financing, 1978 Duke. L.J. 321 (1978).
} 
gent, or more so, than government regulation? Is competitive innovation in cost containment feasible? Could provider cartels be prevented from continuing to call the tune?

Weiner never joins the issue on these interesting empirical questions because he persists in thinking that $I$, true to his stereotype, perceive the issue only in theoretical, even ideological, terms. Yet it would appear from Weiner's footnote 51 that he and I share a philosophical preference for private over governmental solutions to problems of public policy. Perhaps the only problem is that Weiner has yet to appreciate the practical value of removing distortions of private incentives so that market forces can stimulate the complex world to conform more nearly to people's desires.

There appears, however, to be a more fundamental blind spot in Weiner's thinking, one so pervasive that it causes him to deny the very legitimacy of thinking about nonregulatory alternatives. He seems to believe that a political choice of regulation (a) has been made and (b) must be respected, and that therefore my broad skepticism, whether right or wrong, is not only irrelevant but a bit subversive. This view may be challenged on two levels.

First, it is far from clear that a definitive and final decision to rely solely on regulation has in fact been made. Indeed, many cumulatively crucial choices-for more or less regulation, for broader or narrower regulatory conerage (of HMOs, home health services, doctors' offices, and so forth), for liberality or strictness in particular regulatory decisions, for tolerating, encouraging, or suppressing various forms of competition, for one or another model of national health insurance, and so on-remain to be faced. Weiner admits that some of this agenda is open when he asks me to consider how competition and regulation can be blended usefully. ${ }^{29}$ But surely my Comment, showing why regulation of the supply side of the market in order to control demand is an imperfect tool, is an essential preamble to any such effort to reconcile seemingly conflicting approaches. Weiner's criticism that $I$ have neglected this dimension in analyzing regulation is easily refuted by reference to my other writings, which have highlighted the ways in which regulation may, but need not, suppress such useful forms of competition as HMOs. ${ }^{30}$ Moreover, although Weiner had no way of knowing it, the paper he was criticizing is to be a chapter in my forthcoming book tentatively entitled Competition in a Regulated Health Care System.

Much more serious are the implications of Mr. Weiner's refusal to concede that $\mathbf{I}$ have a clear right, as a scholar, to question government's

\footnotetext{
29 Weiner, supra note 1 , at 32.

${ }^{30}$ Havighurst \& Bovbjerg, Professional Standards Review Organizations and Health Maintenance Organizations: Are They Compatible? 1975 UTAH L. Rev. 381 (1975); Havighurst, Health Maintenance Organizations and the Health Planners, 1978 UTAH L. REv. 123 (1978); Havighurst, supra note 9, at 1204-15.
} 
choice of regulation once that choice has been made. The source of this vague but distinctly repressive impulse lies in Weiner's apparent reverence for the political process, as revealed in his lengthy recitation of the theory of interest-group liberalism-the idea that competing interests will all balance out in the political process and approximate the "public interest."31 This discussion reveals no awareness of the large volume of scholarship by political scientists and economists that casts grave doubts on the theoretical as well as the empirical reliability of that model as a vehicle for advancing the public welfare. Consider, for example, the phenomenon of "pork barrel" legislation and the difficulty of aggregating interests and registering the respective strengths of competing preferences. Weiner and other critics who rightly regard the "free market" model as too simplistic to substitute for policy should be wary of accepting uncritically a textbook model of the political process.

Weiner's acceptance of the output of political institutions, particularly regulatory institutions, is not shaken by the poor performance of regulation in other industries, by health sector regulation's unimpressive performance to date, or by my showing of the substantial political difficulties of doing the cost-containment job. The reason for his-and perhaps for many other people's-unshakeable acceptance of regulation is that in their view regulation, by definition, cannot fail: As a political enterprise, its results are automatically legitimized and can be challenged only in the particular, not in the aggregate. Consider, for example, this explicit attempt by Weiner to limit the scholar's agenda: "How the regulatory agency balances ... varying interests at any one point in time with respect to any one decision is the proper subject of legal, political, and economic analyses of the regulatory process." ${ }^{32}$ A careful reading of Weiner indicates that he is saying much more than that I should accept regulation as a fait accompli and get on to more practical matters.

Weiner also takes the view that a scholar who disputes the need for a regulatory scheme that is already in place is expressing a counterrevolutionary political preference only, and is sailing under false colors if he cloaks his argument as academic analysis. Thus, he says that, given the political context, "it is inappropriate to evaluate regulation against any abstracted standards or norms ... without acknowledging that any such effort reflects the value structure of the commentator, and not necessarily the value structure of the [regulating] agency." ${ }^{33}$ Specifically, Weiner is objecting to my statement that "there is no reason whatsoever to think that the political processes yielding [through regulation some ultimately stable share of GNP devoted to health] ... will have come anywhere near finding

\footnotetext{
"Weiner, supra note 1 , at 18-20.

${ }^{32} I d$. at 20 (emphasis added).

${ }^{33}$ Id. (emphasis added).
} 
the socially optimal level of spending on health care." 34 The objection to my passing reference to a social optimum is fully answered in an earlier article in which James Blumstein and I carefully discussed the use of such a purely hypothetical benchmark in thinking about public policy towards health care. ${ }^{35}$

I would readily admit that measuring regulation by the yardstick of theoretical optimality-a highly and perhaps perfectly democratic yardstick, it should be noted-would not justify overturning a regulatory scheme unless (1) that scheme could not be improved and (2) there was a better way to approach the posited objective. But I have argued, first, that health care regulation cannot be sufficiently strengthened without greatly increased arbitrariness and the sacrifice of values that most people would regard as important and, second, that a system affording consumers a wide range of choice under appropriate cost constraints would outperform any acceptable form of regulation.

Once my own positions are correctly stated, it turns out that Weiner agrees with me on several points. Thus, despite his sweeping attempt to discredit my analysis, he ends up by accepting my gloomy assessment of regulation for all aspects of the health care enterprise except hospitals. ${ }^{36}$ This indicates that the real differences between us may be less fundamental than his tone would suggest. That he agrees with me on the potential utility of HMOs has already been noted. Finally, if Weiner could get over his romantic or merely ill-considered acceptance of the processes of interest-group liberalism and accept the need to demand that government do as well (by some standard, which the political process may help to define) as some realistic alternative, there seems some chance that he would accept at least the theoretical framework of my analysis and my definition of the empirical issues.

Despite our areas of agreement, however, Weiner and I might still differ over the allocation of decision-making responsibility on some significant matters. It is regrettable that he did not respond to my discussion ${ }^{37}$ of the desirability of leaving room for individuals to express (with costs in view) their widely varying preferences about the highly personal matter of health care. Since it was my stated position that there is no "one right way" to deal with health problems and that the system can safely be arranged to permit a considerable range of individual choice, we need to know why Weiner might think that collective decisions, restricting choice, would be preferable. What worries me is that, in passing over my arguments for facilitating individual choice, Weiner may have signified a disinterest in

\footnotetext{
${ }^{34}$ Havighurst, supra note 2, at 315-16 (emphasis added).

${ }^{35}$ Havighurst \& Blumstein, supra note 19, at 15-20.

${ }^{36}$ Weiner, supra note 1 , at 25.

${ }^{37}$ Havighurst, supra note 2, at 317-19.
} 
people's preferences comparable to that which characterizes that shadowy cultural elite increasingly being referred to as "the new class." 38 This "new class" was recently described by Paul $\mathrm{H}$. Weaver, in an illuminating article on the social issues involved in government regulation, as "that rapidly growing and increasingly influential part of the upper-middle class that feels itself to be in a more or less adversary posture vis-à-vis American society and that tends to make its vocation in the public and not-for-profit sectors." ${ }^{39}$ Weaver sees "the real animus of the new class . . . [as being] against the liberal values served by corporate capitalism and the benefits these institutions provide to the broad mass of the American people: economic growth, widespread prosperity, material satisfactions, a sense of nationhood, a belief in an open and self-determined future, and the many options and freedoms that these make possible for ordinary citizens." 40

There is, unfortunately, some slight evidence-again in the unconsciously revealing footnote 51 -that Weiner shares this "new class's" antagonism toward what Weaver calls "acts of consumption by consenting adults." 41 In conditioning his acceptance of "consensual rationing" on whether it "can be as stringent as government rationing," Weiner is, like the new class, "working against the widespread enjoyment of consumer goods and services that liberal capitalism makesspossible." 42 My own view is that the ultimate goal is not stringency for its own sake but an allocation of resources in accordance with people's revealed preferences and that political processes are incapable of determining, measuring, and giving appropriate effect to those preferences. Indeed, as political processes fall more and more under the control and influence of "the new class," they seem less and less likely to serve pluralistic values that I regard as important, more stifling indeed than mere "bureaucracy" ever was. There is no doubt that "the new class" is highly active in health sector regulation and that important values are at stake. Perhaps it is as well to draw these lines explicitly and to let the overriding issue concerning the future scope of health care regulation be seen as, quite simply, whether this is any longer a liberal democracy in which there is a presumption in favor of the individual's right to choose for himself and to have his preferences catered to in the economic marketplace.

To conclude, Weiner's Comment reflects fairly accurately the conventional wisdom favoring regulation in the health care industry, and is also a typical expression of the prevailing bias in favor of "black box" solutions

\footnotetext{
ss See, e.g., I. Kristol, Two Cheers for Capitalism 27-31 (1978).

so Weaver, Regulation, Social Policy, and Class Conflict, PUB. InTERest, Winter 1978, at 45 ,

${ }^{40} I d$. at 60.

1 Id. at 61 .

12 Id. at 60-61.
} 59. 
to policy problems, using "command-and-control modules," that is deplored by Charles L. Schultze in The Public Use of Private Interest. If Weiner's definition of the issues and his strictures on scholarship were to be accepted, it would seriously narrow the range of the health policy debate, which I firmly believe should be expanded both into the value questions alluded to above and into the practical problems of restoring competition and fostering privately initiated change. Thus, while Weiner has asked me to join the throng of people already engaged in trying to make regulation work within the context of the conventional wisdom, I would suggest that he join the small cadre that is working on neglected alternatives. I still do not know for certain whether there is some basic value preference, or only a debatable (though potentially self-fulfilling) prophecy of future political choices, that keeps him from joining in this effort. 
